\title{
Territórios etnoeducacionais: ressituando a educação escolar indígena no Brasil
}

\author{
Maria Aparecida Bergamaschi * Fernanda Brabo Sousa * * \\ http://dx.doi.org/10.1590/0103-7307201507709
}

\section{Resumo}

Neste artigo apresentamos um estudo do decreto presidencial no 6.861, que criou os Territórios Etnoeducacionais, discorrendo sobre possíveis mudanças que o documento anuncia para a política escolar indígena no Brasil, desde 2009, ano de sua edição, até outubro de 2013, quando foi publicada a portaria no 1.062, do Ministério da Educação, instituindo o Programa Nacional dos Territórios Etnoeducacionais. Metodologicamente, assentamos o pensamento numa metáfora que teve como inspiração a instalação artística "Nosso Norte é o Sul", de Yanagi Yukinori (8- Bienal do Mercosul, Porto Alegre, RS, 2011), cujo "território das formigas", construído ao longo do evento, se mostrou fecundo para pensar possibilidades vislumbradas a partir desses documentos. 0 decreto e a portaria, ao ressituarem a política de educação escolar indígena, interferem não só * Departamento de Estudos Básicos, Programa de PósGraduação em Educação, Faculdade de Educação, Universidade Federal do Rio Grande do Sul (UFRGS), Porto Alegre, RS, Brasil. cida.bergamaschi@gmail. com

* * Programa de Pós-

Graduação em Educação, Faculdade de Educação, Universidade Federal do Rio Grande do Sul (UFRGS), Porto Alegre, RS, Brasil. fernanda_brabo@yahoo. com.br na organização territorial, mas principalmente nas formas de gestão e condução das escolas, inserindo com maior ênfase o protagonismo ameríndio nos processos de educação escolar.

Palavras-chave: Territórios Etnoeducacionais, políticas educacionais indígenas, educação indígena 


\title{
Ethnical educational territories: repositioning the indigenous school education in Brazil
}

\begin{abstract} In this article, we present a study of the Presidential Decree number 6.861 - which created the ethnical educational territories - and discuss possible changes that the document announces for the indigenous schooling policy in Brazil since 2009, when it was edited, until October 2013, when the No 1.062 ordinance by the Education Ministry was published establishing the Programa Nacional dos Territórios Etnoeducacionais (Ethnical Educational Territories National Program). We use a metaphor inspired by the art installation called "Nosso Norte é o Sul" (Our north is the south), by Yanagi Yukinori (8th Mercosul Biennial, Porto Alegre, RS 2011), in which the "territory of ants", built during the event, proved to be a fertile soil for thinking about the possibilities perceived on those documents. Both the decree and the ordinance, by repositioning the indigenous school education policy, interfere not only with the territorial organization, but also with school managing and administration, more emphatically setting the Amerindian protagonism in school education processes.
\end{abstract}

Keywords: Ethnical Educational Territories, indigenous educational policies, indigenous education, Brazil 


\section{Prelúdio}

No ano de 2009, o governo federal editou o Decreto $n$ ㅇ 6.861, criando uma nova situação política e jurídica na história da educação escolar indígena no Brasil: os Territórios Etnoeducacionais - TEEs. Com uma proposta original, no que diz respeito ao reconhecimento das identidades étnicas dos povos indígenas, e a possibilidade de uma gestão mais autônoma de seus processos escolares, ao aliar a questão educacional à territorial, essa política inaugura um novo momento no processo histórico de protagonismo escolar indígena. Em linhas gerais, a ideia de território etnoeducacional significa um movimento de organização da educação escolar indígena em consonância com a territorialidade de seus povos, independentemente da divisão política entre estados e municípios que compõem o território brasileiro.

Passados mais de quatro anos da criação do Decreto, o tema foi retomado com a publicação da Portaria nํ⒈062, de 30 de outubro de 2013 do Ministério da Educação, que instituiu o Programa Nacional dos Territórios Etnoeducacionais - PNTEE. No entanto, além da complexidade de seu fazer-se, pré-sentimos o desconhecimento dessa política por grande parte das lideranças e dos professores indígenas, bem como dos agentes envolvidos na sua efetivação. Diante dessa situação, colocamos algumas indagações: Quais os significados dos territórios etnoeducacionais para a educação escolar indígena? Que relevância apresentam ao movimento dos povos indígenas por autodeterminação e afirmação de suas identidades étnicas? Como podem ser afetadas as escolas indígenas a partir de uma reterritorialização? De fato, verifica-se uma reterritorialização? O que de novo acrescenta a Portaria publicada quatro anos após do Decreto?

Refletindo sobre essas e outras questões que envolvem o pensar a educação escolar indígena no bojo da pesquisa ${ }^{1}$ que nos envolveu nos últimos anos e motivadas pela investigação específica de mestrado² que direcionou o olhar para a política dos Territórios Etnoeducacionais, organizamos este artigo, cuja autoria coletiva é resultado de uma escrita a quatro mãos. Debruçadas sobre os dados de que dispúnhamos até então, fomos positivamente surpreendidas, em outubro de 2013 , pela publicação da Portaria Ministerial nำ1.062, sobre a qual, por complementar a reflexão que aqui dispomos, não

1. Pesquisa "Educação Ameríndia e Interculturalidade", realizada no período de 2011-2013, cujo Projeto foi registrado no portal de pesquisas da UFRGS sob o número 20357, financiado pelo CNPq, processo $n^{0}$ 470726/2011-3, e coordenado pela professora Dra. Maria Aparecida Bergamaschi.

2. Dissertação de Mestrado Reterritorializando a Educação Escolar Indígena: reflexões acerca dos Territórios Etnoeducacionais, realizada por Fernanda Brabo Sousa no período de 2011-2012, com bolsa integral da CAPES, e defendida no Programa de Pós-Graduação em Educação da UFRGS em fevereiro de 2013. 
nos furtamos a tecer considerações, embora germinais, em função do pouco tempo para observar os seus desdobramentos.

Considerando o caráter recente dos documentos em questão e a escassez de estudos sobre as proposições e as repercussões do Decreto $n$ ำ6.861/2009, este artigo reflete acerca dos processos de criação, implementação e pactuação de territórios etnoeducacionais, por meio de um mostrar consciente. Marcadas teoricamente por leituras de Michel Maffesoli $(1996,1998)$, tomamos aqui o “mostrar consciente” como um olhar atento às minúcias daquilo que se olha, buscando compreender o que é; mostrar sem a necessidade de ter de demonstrar, fugindo à tentação do dever ser, reconhecendo as potencialidades presentes naquilo que se olha e isentas do jugo moral sobre um presente que está se fazendo (Maffesoli, 1998). Embora motivadas por muitas perguntas, mais do que sugerir respostas, convidamos a conhecer e a pensar coletivamente os caminhos da educação escolar indígena no País, considerando o que nos apresentam os Territórios Etnoeducacionais. Para tal, utilizaremos o recurso estético da metáfora, de modo a descrever o fenômeno estudado, buscando compreendê-lo sem, no entanto, pretender explicá-lo.

\section{"Território das Formigas": metáfora de uma política em construção}

Exercício de iniciação: imaginemos uma caixa de acrílico transparente, contendo uma comunidade de formigas. Elas possuem, aparentemente, alimento, luz e moradia segura. Aos poucos, aquele espaço emoldurado que lhes foi destinado parece tornar-se insuficiente para suas necessidades, e elas passam a procurar caminhos para além da caixa de acrílico, tal qual fazem em terras livres, ultrapassando os limites impostos por forças externas ao formigueiro.

Há um caminho, um tubo de plástico que parece ser a saída para a busca de algo maior. No fim desse tubo, vários outros, e esses levam a outras caixas de acrílico diferentes, mais estreitas e retangulares, cada qual com areia de diversas cores. As novas caixas, por sua vez, são interligadas por outros tubos, formando um entrecruzamento de caminhos possíveis. As formigas, em um vaivém de caminhos, espalham-se pelas caixas, pelos tubos e pelas cores, formando novas comunidades, dividindo-se, reagrupando-se e misturando-se entre si e entre a areia de vários tons.

Exercício de imersão: imaginemos agora que as formigas sejam pessoas. Os grãos de areia, fronteiras geográficas, políticas e administrativas; os tubos entre- 
cruzados, caminhos de relação entre essas pessoas, suas comunidades de origem, novas comunidades.

Nesse movimento interfronteiras as bandeiras vão se desfigurando, uma vez que a areia colorida é transportada (entre os tubos, pelas formigas), construindo novos desenhos. As bandeiras, meras representações de territórios no pensamento moderno, ou seja, de extensões arbitrárias de terras delimitadas por um Estado ou governo, cedem lugar a outras formas, produzindo, para além dos territórios nacionais esquadrinhados, territorialidades diversas, que contemplam outras noções de cultura e identidade.

Se reconhecermos que, tal qual ocorreu nos territórios das formigas, nós, humanos, também temos necessidades próprias de territorialidades para além das formas geográficas recortadas no globo terrestre, como entender que divisões territoriais arbitrárias sejam impostas aos povos indígenas, sem considerar suas cosmovisões? ${ }^{3}$ Ao anular as especificidades territoriais de cada sociedade indígena, concedendo-lhes, como se fosse um favor, caixas de acrílico com moradia e alimento, isto é, terras indígenas demarcadas e definidas pela União, anulam-se também territorialidades, culturas, identidades, histórias e visões de mundo que uma caixa de acrílico é incapaz de abarcar.

Mesmo nos casos em que as terras indígenas compreendem espaços para além da casa e seus arredores, ainda assim a territorialidade é restrita pelos limites demarcados para um transitar mais amplo. Buscando trilhar um caminho avesso a essa situação e considerando as territorialidades indígenas, se configuram os territórios etnoeducacionais.

A instalação artística “Nosso Norte é o Sul”, de Yanagi Yukinori, exibida na 8 ${ }^{\text {a }}$ Bienal do Mercosul (Porto Alegre, RS, 2011), questiona a forma como fronteiras e identidades são construídas, além das noções de território e nação constituídas na modernidade ocidental. Segundo a curadoria da exposição, a obra

mostra as bandeiras dos países do bloco geopolítico do chamado Cone Sul, complementadas pelas das Guianas, territórios situados na América do Sul, porém distanciados culturalmente do resto do continente por sua condição colonizada ou remota. As

3. Segundo Freitas (2008), há uma diferenciação entre os significados de território no pensamento moderno ocidental e território indígena. De acordo com a autora, “a noção de território no pensamento moderno remete às ideias de fronteira e divisa" (p.17), delimitando rigidamente extensões arbitrárias de terras, em alusão ao domínio de um Estado, governo ou nação. Freitas (2008) afirma que "as sociedades indígenas das terras baixas da América do Sul tendem a representar seus territórios como espaçostempo indissociáveis da vida de seus habitantes" (p.18), de modo que o pertencimento à terra se mistura a um sentimento de parentesco com essa terra. 
formigas vão construindo seus túneis, estabelecendo pontes entre as nações alegorizadas nas bandeiras, minando a integridade visual delas e propondo uma utópica integração regional (José Roca, citado por Ramos, 2011, p. 175).

Quando nos deparamos com essa instalação artística, percebemos nela a concretude visual da política de etnoterritórios. A configuração espacial e o alcance dos territórios etnoeducacionais mostraram-se palpáveis, para além do plano das ideias, tal qual internamente visualizado no campo da imaginação.

0 texto de um documento legal, no entanto, dificilmente traduz as imagens visivas formuladas por seus redatores. A dureza que, em geral, recobre esse tipo de texto não permite a visualização da imagem e seus intentos para além das palavras rigidamente dispostas. Dessa forma, o uso da metáfora pretende situar os territórios etnoeducacionais no campo do visível, do tatilmente possível, isto é, do sensível.

A metáfora contenta-se em descrever, sem a pretensão de explicar algo ou de explicar-se. Segundo Maffesoli (1998), a metáfora pode auxiliar na compreensão de um fenômeno, possibilitando maior percepção de suas significações, mas sem enclausurar aquilo que pretende descrever. Como um apoio metodológico para elaborar uma razão sensível, ou uma sensibilidade intelectual, a metáfora

é um instrumento privilegiado, pois, contentando-se com descrever aquilo que é, buscando a lógica interna que move as coisas e as pessoas, reconhecendo a parcela de imaginário que as impregna, ela leva em conta o "dado" [destaque no original], reconhecendo-o como tal e respeita suas coibições (Maffesoli, 1998, p. 152).

Portanto, por ora freamos a tentação de interpretar e, uma vez esgotado, momentaneamente, o recurso metafórico para o fim ao qual se destina, é hora de ater-se às palavras que, oficialmente, compõem e descrevem a política de territórios etnoeducacionais, constantes no Decreto $n^{\circ} 6.861 / 2009$.

\section{Esmiuçando o Decreto n 6.861/2009}

Buscando em dicionários" o significado da palavra "esmiuçar", escolhemos "explicar minuciosamente”, “descrever ou narrar com pormenores”. Esmiuçar origina-se do latim, minutia, que significa "parcela ou volume muito pequeno", correspondente

4. Foi consultado o dicionário on-line Priberam.pt, disponivel em http://www.priberam.pt/ em português usual a "minúcia”. Nesse sentido, esmiuçar o Decreto significa considerar as minú- 
cias do documento e as decorrências de sua publicação, que é o que nos dispomos a fazer na presente seção.

Quando, em maio de 2009, o Decreto n- 6.861 foi expedido, gerou controvérsias e desconfianças entre lideranças indígenas, possivelmente por sentirem-se excluídas do processo de elaboração do documento. Num primeiro momento, parecia, aos grupos que discutiam o Decreto, que este havia sido imposto "de cima para baixo", causando desconforto nas instâncias onde a educação escolar indígena acontece.

Por isso, naquele ano, período em que se organizava a I Conferência Nacional de Educação Escolar Indígena - CONEEI -, ocorrida em novembro de 2009, uma parte dos representantes indígenas desconsiderou o Decreto, por não ter sido previamente discutido com as comunidades envolvidas. Também porque, segundo avaliações que se faziam naquele momento, não contemplava um dos principais itens apontados pela Conferência, qual seja, a criação de um Sistema Próprio de Educação Escolar Indígena no Brasil, contando com um Conselho Nacional de Educação Escolar Indígena e um Fundo Nacional da Educação Escolar Indígena.

O documento final da I CONEEI sustentou que deveria ser criado um Sistema Próprio de Educação Escolar Indígena

em âmbito nacional, com ordenamento jurídico específico e diferenciado, sob a coordenação do Ministério da Educação (MEC) e com a garantia do protagonismo dos povos indígenas em todos os processos de criação, organização, implantação, implementação, gestão, controle social e fiscalização de todas as ações ligadas à educação escolar indígena, contemplando e respeitando a situação territorial de cada povo indígena.... 0 Sistema Próprio de Educação Escolar Indígena deverá reconhecer, respeitar e efetivar o direito à educação específica, diferenciada, intercultural, comunitária e de qualidade, especialmente no que se refere à questão curricular e ao calendário diferenciado, que definam normas específicas, que assegurem a autonomia pedagógica (aceitando os processos próprios de ensino e aprendizagem) e a autonomia gerencial das escolas indígenas como forma de exercício do direito à livre determinação dos povos indígenas, garantindo às novas gerações a transmissão dos saberes e valores tradicionais indígenas (Documento final da I Conferência de Educação Escolar Indígena, 2009b, p. 4).

A I CONEEI foi realizada após um ano de conferências locais e regionais, com seminários, encontros e debates, visando delinear políticas públicas e orientar as agendas 
políticas, de modo a contemplar demandas e especificidades da educação escolar indígena no Brasil.

Conquanto tenha sido aprovado antes das deliberações da Conferência, o Decreto no 6.861 veio ao encontro dos três eixos principais de discussão, a saber: “Educação Escolar, Territorialidade e Autonomia dos Povos Indígenas”; "Práticas Pedagógicas, Participação e Controle Social e Diretrizes para a Educação Escolar Indígena”; e "Políticas, Gestão e Financiamento da Educação Escolar Indígena”. Segundo nossa avaliação, o Decreto apresenta avanços significativos em atenção às especificidades e à territorialidade de cada povo indígena. Nesse sentido, quais são as principais mudanças introduzidas pelo Decreto?

Já nas suas primeiras disposições, o Decreto 6.861/2009 aponta a principal mudança, qual seja, a de que "a educação escolar indígena será organizada com a participação dos povos indígenas, observada a sua territorialidade e respeitando suas necessidades e especificidades" (Decreto Presidencial nำ6.861, 2009a, § 1ํํ). Segue dispondo sobre os objetivos e a organização da educação escolar indígena e, em parágrafo único, entre os artigos sexto e sétimo, define o que se deve depreender da categoria "território etnoeducacional".

Cada território etnoeducacional compreenderá, independentemente da divisão político-administrativa do País, as terras indígenas, mesmo que descontínuas, ocupadas por povos indígenas que mantêm relações intersocietárias caracterizadas por raízes sociais e históricas, relações políticas e econômicas, filiações linguísticas, valores e práticas culturais compartilhados (Decreto Presidencial nº.861, 2009a).

O Decreto oferece possibilidades para a implantação e a execução dos etnoterritórios, com indicações das responsabilidades de cada ente envolvido no processo, inclusive em relação a dotações orçamentárias. No artigo $5^{\circ}$, destrinça a que se presta o apoio técnico e financeiro, a cargo prioritariamente do Ministério da Educação: “construção de escolas; formação inicial e continuada de professores indígenas e de outros profissionais da educação; produção de material didático; ensino médio integrado à formação profissional; alimentação escolar indígena” (Decreto Presidencial no 6.861, 2009a).

Além disso, considerando a territorialidade étnica, independente das unidades federativas, o governo federal parece recuperar a responsabilidade imediata sobre a 
educação escolar indígena, com especificidade de papéis para cada esfera administrativa. Isso aponta para uma expressiva relevância do Conselho Nacional de Educação Escolar Indígena e dos Conselhos Estaduais, no sentido de fortalecerem-se, em colaboração mútua, a fim de se fazerem ouvir institucionalmente em suas reivindicações em prol da educação escolar indígena específica e diferenciada, de qualidade, e em respeito e consonância às comunidades envolvidas.

Vale frisar que um dos pontos mais importantes do Decreto se refere à participação efetiva dos povos indígenas em todas as etapas da gestão da educação escolar, sendo a própria criação da escola iniciativa ou reivindicação da comunidade interessada, o que deixa claro o caráter autônomo do processo educacional. Em parágrafo único, o Decreto nำ 6.861 diz: “A escola indígena será criada por iniciativa ou reivindicação da comunidade interessada, ou com sua anuência, respeitadas suas formas de representação" (Decreto Presidencial no 6.861, 2009a).

Nesse sentido, o texto do Decreto expressa uma das recomendações presentes na Convenção 169 da OIT, a qual, no artigo 27, afirma:

os governos deverão reconhecer o direito desses povos de criar suas próprias instituições e sistemas de educação, desde que essas instituições observem as normas mínimas estabelecidas pela autoridade competente em consulta com esses povos. Recursos apropriados para essa finalidade lhes deverão ser facilitados (Convenção no 169 sobre povos indígenas e tribais em países independentes e Resolução referente à ação da OIT sobre povos indígenas e tribais, 2005, p. 45).

Consideramos também que o teor do Decreto no 6.861/2009 dialoga com o texto final da I CONEEI (2009). Esse diálogo é expresso, por exemplo, nas considerações que o documento final da conferência faz sobre a política de criação dos territórios etnoeducacionais, ratificando algumas das garantias legais já expressas no Decreto:

0 governo federal somente implantará os Territórios Etnoeducacionais com a anuência dos povos indígenas a partir de consulta pública ampla com a realização de seminários locais, regionais e/ou estaduais para esclarecimentos sobre a proposta de implantação e implementação dos Territórios Etnoeducacionais, avaliando a sua viabilidade, sua área de abrangência em relação aos povos e Estados, considerando os novos marcos legais a serem construídos e os planos de trabalho dos Territórios Etnoeducacionais. 0 Governo Federal 
garantirá aos povos indígenas que não concordarem em adotar ou que ainda não definiram o modelo de gestão baseado nos Territórios Etnoeducacionais o envio de recursos de igual qualidade para a educação escolar indígena (Documento final da I Conferência de Educação Escolar Indígena, 2009b, p. 5).

O documento da CONEEI especifica também como deve se dar a implantação da referida política, mostrando que grande parte do debate que produziu o documento final da conferência levou em consideração o conteúdo do Decreto que criou os Territórios Etnoeducacionais.

A implantação dos Territórios Etnoeducacionais deve ser feita através de amplo processo
de discussão sobre: marcos legais específicos; formação presencial de professores indíge-
nas e de demais profissionais indígenas; regulamentação da oferta de ensino a distância;
construção das escolas indígenas de acordo com a decisão das comunidades; controle so-
cial; gestão dos recursos financeiros destinados às escolas indígenas; implantação ou não
de todos os níveis e modalidades de ensino nas aldeias; planos de trabalho dos Territórios;
mecanismos de punição para assegurar que os entes federados cumpram com suas respon-
sabilidades (Documento final da I Conferência de Educação Escolar Indígena, 2009b, p. 5).

A educação escolar indígena, com respaldo legal para "a utilização de suas línguas maternas e processos próprios de aprendizagem” (Constituição da República Federativa do Brasil, 1988, art. 210, parágrafo $2^{\circ}$ ), é assegurada juridicamente pela atual Constituição Federal, marco legal para o "tempo dos direitos”, como anunciam lideranças indígenas, ao se referirem à legislação que oficialmente supera o aspecto integracionista da instituição escolar destinada às sociedades indígenas, que historicamente vigorou. A categoria "escola indígena”, no entanto, só se tornou legalmente oficial a partir de 1999, com as Diretrizes Curriculares Nacionais da Educação Escolar Indígena, estabelecidas pelo Parecer nํ14/1999 e pela Resolução nํㅜ 3/1999.

Embora, em muitos sentidos, a legislação se mostre mais avançada do que as práticas escolares destinadas aos povos indígenas, é importante ressaltar que os modos como vem se fazendo escola nesse período, após a Constituição Federal de 1988, começam a se modificar, talvez muito mais pelo movimento desses povos, que reivindicam a condução das políticas e passam a ter maior protagonismo.

Reconhecemos que o Plano Nacional de Educação de 1993 e a Lei de Diretrizes 
e Bases da Educação Nacional de 1996 também apresentam avanços com relação à educação escolar indígena, mas apenas com a Lei nํㅜ 10.172 de 2001 (Plano Nacional de Educação) foi assegurada juridicamente a tão almejada autonomia, ao afirmar que cabe às comunidades indígenas a prerrogativa de elaborar e implementar seus processos pedagógicos, "quanto ao uso de recursos financeiros públicos para a manutenção do cotidiano escolar, garantindo a plena participação de cada comunidade indígena nas decisões relativas ao funcionamento da escola" (Lei n- 10.172, 2001, p. 53).

Observamos que o Decreto n-6.861/2009 incorpora anseios de autonomia postos em documentos anteriores. Outro exemplo é o Referencial Curricular Nacional para Escolas Indígenas - RCNEI (1998), que alude em seu texto ao respeito à autodeterminação e à autoafirmação dos povos originários:

Os povos indígenas em todo o mundo, no contexto atual de inserção nos estados nacionais, têm contato com valores, instituições e procedimentos distintos dos que lhes são próprios. Eles têm o direito de decidir seu destino, fazendo suas escolhas, elaborando e administrando autonomamente seus projetos de futuro. Desse modo, a escola indígena faz parte desse projeto de construção autônoma do projeto societário. Para isso, a comunidade deve participar da definição do projeto político-pedagógico da escola, das decisões pedagógicas e curriculares e da organização e gestão escolares (Referencial Curricular Nacional para as Escolas Indígenas, 1998).

Todavia, até a primeira década do século XXI não foram instituídos mecanismos operacionais específicos e eficazes no sentido de ordenar e normatizar o atendimento diferenciado anunciado na legislação para as escolas indígenas. Em decorrência disso, observamos secretarias estaduais e municipais de educação desarticuladas, implementando escolas em Terras Indígenas de forma semelhante às escolas urbanas, desconsiderando os processos próprios de aprendizagem e os sistemas educacionais específicos de cada povo.

Com a criação dos territórios etnoeducacionais, algumas lacunas, no sentido de propiciar concretamente a autodeterminação sugerida pelos documentos legais, começaram a ser preenchidas, como, por exemplo, o que anuncia o Decreto 6.861/2009 no parágrafo segundo, item VI, ao elencar como um dos objetivos da educação escolar indígena a "afirmação das identidades étnicas e consideração dos projetos societários definidos de forma autônoma por cada povo indígena” (Decreto Presidencial 
$\mathrm{n}$ - 6.861, 2009). 0 reconhecimento, de forma mais contundente, das territorialidades indígenas reflete também no acolhimento das especificidades de cada sociedade e na autonomia de suas escolas. Abre-se espaço para a participação efetiva dos povos originários em todas as etapas do processo de implementação da escola, desde a decisão pela criação até as formas de geri-la, como consta do parágrafo único: "A escola indígena será criada por iniciativa ou reivindicação da comunidade interessada, ou com sua anuência, respeitadas suas formas de representação" (Decreto Presidencial no 6.861, 2009).

A leitura apurada do Decreto, adentrando em suas minúcias, possibilita perceber o seu alcance político. Um decreto5, embora acabe por desempenhar, na prática, papel de ato do legislativo, pode funcionar como uma espécie de sugestão de mudança na cultura política, sem o caráter impositivo de uma lei. Daí, talvez, o costume de apresentar tempos verbais no futuro do presente, em sua maioria, sugerindo o que poderia acontecer a partir de sua publicação.

Entre outros sentidos, podemos compreender o Decreto como uma espécie de brecha entre os documentos legais criados até 2009 e o documento final da I CONEEI. Isso porque, atentando às proporções e ao alcance do referido decreto, ele pode significar uma ponte entre a legislação e seus aparatos burocráticos, as inovações da I CONEEI e as recentes articulações dos movimentos indígenas. Ao indicar possibilidades para a autonomia das escolas indígenas, parece aproximar-se um pouco mais dos sistemas de educação indígenas da América Latina, no sentido de construir alternativas mais independentes das mãos governamentais e criar sistemas de educação escolar autônomos. Isso não significa desvencilhar-se do poder do Estado sobre as macroações da educação escolar, mas, sim, prover um maior empoderamento indígena para redefinir os contornos dos modelos já existentes.

A necessidade de legitimar e oficializar o direito dos povos originários de realizar

5. Devido à morosidade dos processos legislativos brasileiros, grande parte dos documentos legais que regulamentam direitos de minorias sociais no País constituem-se de decretos, resoluções e pareceres, ou seja, atos do executivo nacional. Não se pode entender, no entanto, que se trata simplesmente de ações presidenciais isoladas das reivindicações e pressões dos movimentos sociais; no caso dos direitos indígenas, o legal só se formaliza e se concretiza porque há movimentação das lideranças e das comunidades indígenas. suas próprias escolhas políticas vem de uma trajetória específica, no sentido do caminho proposto por Bengoa (2000, 2009), como uma emergência política da questão indígena na América. A busca crescente das lideranças indígenas pelo conhecimento apurado das engrenagens estatais proporciona-lhes que participem delas ativamente, sem tudo esperar do poder tutelar e das políticas pro- 
tecionistas de órgãos como o extinto Serviço de Proteção aos Índios - SPI - e a atual Fundação Nacional do Índio, FUNAI. O conjunto de aparatos legais torna-se, desse modo, ferramenta de luta no sentido de afirmar a existência de direitos conquistados.

Em relação às configurações advindas da organização dos etnoterritórios, podemos dizer que o Decreto nำ6.861 procura delinear papéis específicos para cada esfera de governo e para as lideranças indígenas, recomendando a criação de comissões para implementação, acompanhamento e avaliação dos territórios etnoeducacionais. A especificidade de funções não é estabelecida claramente no texto do Decreto, mas isso ocorre nos planos de pactuação de cada etnoterritório. Na prática, esses planos estabelecem as funções de todas as partes envolvidas para a implementação e o funcionamento de um território etnoeducacional, regulamentando o regime de colaboração, de modo a operacionalizar, sinergicamente, os processos e os modos próprios de educação de cada povo indígena, em consonância com os deveres do Estado para com eles. 0 artigo oitavo orienta a elaboração do plano de ação, que deve conter:

I - diagnóstico do território etnoeducacional com descrição sobre os povos, população, abrangência territorial, aspectos culturais e linguísticos e demais informações de caráter relevante;

II - diagnóstico das demandas educacionais dos povos indígenas;

III - planejamento de ações para o atendimento das demandas educacionais; e

IV - descrição das atribuições e responsabilidades de cada partícipe no que diz respeito à educação escolar indígena, especialmente quanto à construção de escolas indígenas, à formação e contratação de professores indígenas e de outros profissionais da educação, à produção de material didático, ao ensino médio integrado à educação profissional e à alimentação escolar indígena (Decreto Presidencial nº 6.861, 2009a).

Importante ressaltar que, nesse processo, estados e municípios são convocados a assumir suas responsabilidades em relação à educação escolar indígena. Cabe apenas aos povos indígenas a decisão de aceitar ou rejeitar a implantação de um etnoterritório, sendo que, de todos os processos de consulta e levantamento já realizados, não houve nenhuma rejeição expressa.

No que tange à efetivação do que diz o Decreto, até 2011 haviam sido pactuados 14 territórios etnoeducacionais, a saber: Rio Negro, Baixo Amazonas, Juruá/Purus, Cone Sul, Povos do Pantanal, Xavante, Xingu, Médio Solimões, Yby Yara - Bahia, 
Mebengokré do Pará, Mapuera, Alto Solimões, Vale do Javari e Cinta-Larga e havia outros em fase de implantação e consulta (Garcia, 2011). Durante o ano de 2012, mais 7 territórios foram pactuados: Timbira, Vale do Araguaia, Tupi Mondé, Tupi Tupari, Txapakura, Ykukatu e Tapajós Arapiuns, perfazendo 21 etnoterritórios ${ }^{6}$, de acordo com dados divulgados pela FUNAI7. Em novembro de 2012, foi publicado edital de contratação de 11 consultores para os territórios etnoeducacionais existentes, com o objetivo de retomar e consolidar a política em questão.

\section{Novos ventos movimentam os territórios etnoeducacionais}

Em meio ao processo de implantação de um programa nacional de formação de professores indígenas, "Saberes Indígenas na Escola” (SECADI/MEC), que atende as reiteradas afirmações do Decreto no 6.861/2009 no que tange à formação de professores, o Ministério da Educação publicou no Diário Oficial da União, no dia 30 de outubro de 2013, uma portaria que institui o Programa Nacional dos Territórios Etnoeducacionais - PNTEE, considerando, entre outros documentos recentes da educação escolar indígena no Brasil, o que dispõe o Decreto n 6.861, de 27 de maio de 2009 (Portaria 1062, l, 2013). O referido documento, composto por sete artigos e assinado pelo Ministro de Estado da Educação, ratifica, em grande parte, o conteúdo do Decreto apresentado neste estudo. Em seu parágrafo 2ํㅜ a portaria (Portaria 1062, 2013) anuncia que

os territórios etnoeducacionais serão espaços institucionais em que os entes federados, as comunidades indígenas, as organizações indígenas e indigenistas e as instituições de ensino superior pactuam ações de promoção da educação escolar indígena, efetivamente adequada às realidades sociais, históricas, culturais, ambientais e linguísticas dos povos e comunidades indígenas.

Na sequência, o texto da Portaria expõe os objetivos, que coincidem com o Decreto, principalmente por anunciar a ampliação e a

6. 0 mapa com os territórios etnoeducacionais pactuados até 0 ano de 2012 pode ser apreciado em: http://6ccr.pgr. mpf.gov.br/institucional/grupos-de-trabalho/educacao/ documentos/mapa-dos-territorios-etnoeducacionaispactuados/view.

7. http://www.funai.gov.br/ultimas/noticias/2012/05_ mai/20120517_08.html qualificação da oferta de educação escolar indígena em todos os níveis; fortalecer o regime de cooperação entre os sistemas de ensino; garantir a participação dos povos originários, observando a territorialidade e as especificidades. Faz uma res- 
salva que assegura aos povos indígenas que não optarem por participar do programa dos Territórios Etnoeducacionais terem acesso isonômico às ações do Programa. Os princípios do PNTEE, anunciados pela Portaria 1.062/2013, afirmam pressupostos contidos na Resolução CNB/CEB nํ5, de 2012, que dizem respeito à gestão e à participação social, à oferta de formação continuada, ao desenvolvimento de pedagogias diferenciadas e ao uso das línguas indígenas, bem como às memórias, à materialidade e à sustentabilidade. A Portaria também traz elementos inovadores em relação ao Decreto n 6.861/2009, na medida em que prevê atenção especial à educação de jovens e adultos, e também à educação profissional e tecnológica, sugerindo a implantação da Rede Federal de Educação Profissional em Terras Indígenas. Além disso, atualiza a demanda da educação escolar indígena em diferentes níveis de ensino, na perspectiva de qualificar a oferta de educação superior, não mencionada no documento precedente. Na Portaria de 2013, há um inciso específico para tratar do tema:

V - educação superior e pós-graduação:

Fomento ao acesso e à permanência de estudantes indígenas na educação superior e pós-graduação, assegurando-lhes estruturas institucionais e pedagógicas adequadas;

a) Apoio a núcleos de estudo e pesquisa de instituições de ensino superior que desenvolvam projetos de educação escolar indígena e estimular o desenvolvimento de pesquisas acerca dos territórios etnoeducacionais;

b) Acompanhamento e avaliação dos programas de reservas de vaga em instituições de ensino superior e de concessão de bolsas destinadas aos estudantes indígenas; e

c) Promoção do desenvolvimento de atividades de ensino, pesquisa e extensão que considere demandas e necessidades das populações indígenas.

Dessa forma, podemos vislumbrar mais um capítulo legislativo federal que se efetiva no sentido de ampliar os direitos indígenas, de modo a diminuir as desigualdades sociais por meio da expressão da autodeterminação de seus povos e de sua autoafirmação identitária.

\section{Epílogo}

O Decreto $n=6.861 / 2009$, referendado agora pela Portaria $n \div 01062 / 2013$, parece possibilitar um fazer-se da educação escolar indígena, na busca de modos próprios de fazer escola, de acordo com as especificidades de cada povo. A gestão mais au- 
tônoma de um território etnoeducacional, junto com a ampliação dos direitos conquistados, pode contribuir para esse fazer-se contínuo da escola indígena, com seus processos próprios de escolarização, aprendizado e ensino.

No entanto, muitas perguntas ainda se mostram sem respostas aparentes no caminhar das políticas públicas em educação escolar indígena. Como conquistar autonomia depois de tantos anos submetidos a uma educação escolar "civilizatória" e diante de tantos anos de tutela do Estado? Como agir dialogicamente para fazer essa escola? A valorização e a afirmação das identidades étnicas contribuem para a construção dessa "nova” escola?

Nessa perspectiva, Bengoa (2009) fala de uma segunda emergência da questão indígena na América. É chegado o tempo da construção de uma nova cidadania indígena, uma “cidadania plena e diferenciada”, como formulou Gersem Baniwa (2010), que possibilite não o pagamento de uma dívida histórica para com os povos indígenas, mas o empoderamento desses povos no sentido macropolítico.

La primera fase del ciclo de la Emergencia Indígena permitió instalar la cuestión de la etnicidad en América Latina. La segunda fase que observamos recién comienza, y planteará el desafio de construir una nueva forma de ciudadanía indígena. Es una segunda fase del proceso de "descolonización interna" [destaques do original]. Los indígenas no tendrían porqué, cuando son mayorías nacionales, regionales o locales, dejarles el poder del Estado a los colonialistas y marginarse en um falso y poco eficiente concepto de autonomía.... ¿No son acaso los indígenas ciudadanos de los países de América Latina, los ciudadanos por antonomasia, los primeros ciudadanos? (Bengoa, 2009, p. 19).

E nós, intelectuais, pesquisadores da academia e estudiosos da educação indígena, que papéis, atribuições e responsabilidades assumimos? Que significados buscamos e produzimos para os territórios etnoeducacionais, e mais, para a autodeterminação e a autoafirmação dos povos indígenas? Acreditamos na possibilidade de ressituar a Educação Escolar Indígena no Brasil?

Nessa reflexão compartilhada, diante de políticas educacionais que configuram a escola indígena no gerúndio, retomamos a metáfora que nos inspirou pensar nos territórios etnoeducacionais e nos perguntamos: como no "território das formigas", também estaríamos esquadrinhados em caixas de acrílico, emoldurados pelas nossas próprias práticas e por políticas que cerceiam nossa liberdade de ação, visão e 
pensamento? Que caminhos traçamos nas identificações, nos estranhamentos, nas aproximações e nos encantamentos com a educação escolar indígena?

Ao desconfigurarem contornos territoriais, as formigas não destroem totalmente as bandeiras, mas constroem outros desenhos que lhes sejam próprios, reterritorializam, ressituam. Ao reivindicarem legitimamente a autonomia de seus processos próprios de educação, apropriando-se étnica e culturalmente da escola que conhecemos, os povos indígenas não contradizem suas tradições. Pelo contrário, a educação escolar indígena possibilita revisitar, reconhecer e reinventar a identidade étnico-cultural de um povo. Assim seguem as formigas, assim seguimos nós. 


\section{Referências bibliográficas}

Baniwa, G. S. L. (2010). Territórios etnoeducacionais: um novo paradigma na política educacional brasileira. Comunicação apresentada na Conferência Nacional de Educação - CONAE, 2010. Brasília: CINEP.

Bengoa, J. (2000). La emergência indígena en América Latina (341pp.). Santiago de Chile: Fondo de Cultura Econômica.

Bengoa, J. (2009, enero/julio). ¿Una segunda etapa de la Emergencia Indígena en América Latina? Cuadernos de Antropología Social, 29, 7-22.

Freitas, A. E. C. (2008). Territórios ameríndios: espaços de vida nativa no Brasil

Meridional. In M. A. Bergamaschi (Org.), Povos indígenas e Educação (pp.17-28). Porto Alegre: Mediação.

Garcia, T. A. (2011). A política brasileira de educação intercultural e a construção dos territórios etnoeducacionais. In Anais da IX Reunião de Antropologia do Mercosul. Curitiba, PR.

Maffesoli, M. (1996). No fundo das aparências (p. 350). Petrópolis: Vozes.

Maffesoli, M. (1998). Elogio da razão sensível (4a ed., p. 205). Petrópolis: Vozes.

Ramos, A. D. (Coord.) (2011). 8ª Bienal do Mercosul. Ensaios de geopoética. Catálogo (p. 192). Porto Alegre: Fundação Bienal Mercosul. Recuperado em 27/11/2013 de http://www.bienalmercosul.com.br/novo/arquivos/publicacão/pdf/Catalogo_ 8Bienal.pdf .

\section{Legislação}

Constituição da República Federativa do Brasil de 1988. Brasília, DF.

Convenção $n^{0} 169$ sobre povos indígenas e tribais em países independentes $e$ Resolução referente à ação da OIT sobre povos indígenas e tribais. Brasília: OIT, 2005.

Decreto Presidencial $n^{0}$ 6.861, de 27 de maio de 2009 (2009a). Dispõe sobre a Educação Escolar Indígena, define sua organização em Territórios Etnoeducacionais e dá outras providências. Brasília, DF.

Diretrizes Curriculares Nacionais para a Educação Escolar Indígena na Educação Básica (2012). Resolução no 5, aprovada em 22 de junho de 2012. Brasil: Conselho Nacional de Educação/Câmara de Educação Básica.

Documento final da I Conferência de Educação Escolar Indígena. (2009b). Ministério da Educação e Cultura. Luziânia-GO, Brasil. 
Lei $n^{0} 10.172$ (2001). Aprova o Plano Nacional de Educação e dá outras providências.

Brasília-DF, Brasil: Ministério da Educação e Cultura.

Lein-13.005/2014. Aprova o Plano Nacional de Educação - PNE e dá outras providências. (2014) Brasil: Ministério da Educação e Cultura.

Parecer 14/1999 (1999). Brasil: Ministério da Educação.

Parecer nำ13/2012 (2012). Diretrizes Curriculares Nacionais para a Educação Escolar Indígena. Brasil: Ministério da Educação e Cultura.

Plano Nacional de Educação 2011-2020. Em tramitação no Senado Federal.

Portaria 1062, de 30 de outubro de 2013 (2013). Institui o Programa Nacional dos Territórios Etnoeducacionais - PNTEE. Brasil: Ministério da Educação e Cultura.

Referencial Curricular Nacional para as Escolas Indígenas (1998). Brasília: DF, Brasil: Ministério da Educação e Cultura.

Resolução CEB, no $3 / 1999$ (1999). Fixa Diretrizes Nacionais para o funcionamento das escolas indígenas e dá outras providências. Brasil: Conselho Nacional de Educação.

Submetido à avaliação em 7 de dezembro de 2013; aceito para publicação em 3 de setembro de 2014 . 